\title{
Advanced diagnostics applied to a self-breathing fuel cell
}

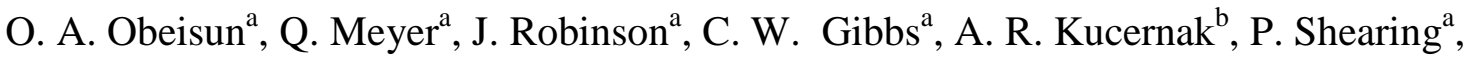 \\ and D. J. L. Brett ${ }^{\mathrm{a}}$ \\ ${ }^{a}$ Electrochemical Innovation Lab, Department of Chemical Engineering, University \\ College London, WC1E 7JE, London United Kingdom. \\ ${ }^{\mathrm{b}}$ Department of Chemistry, Imperial College London, South Kensington London SW7 \\ 2AZ, UK
}

In a self-breathing fuel cell, oxygen is taken directly from ambient air which provides the benefit of reduced system complexity and system operation. This study explores the use of, printed circuit boards (PCBs) as flow field plates to design a self-breathing fuel cell which helps reduce overall volume and cost of the system. It investigates the effect opening ratios have on fuel cell performance using polarization curves and electrochemical impedance spectroscopy. The result obtained indicates that greater opening ratios improve the mass transport properties of the fuel cell but increased Ohmic resistance as a result of the increased openings and reduced area of lands/ ribs respectively. A maximum power density of $188 \mathrm{~mW} \mathrm{~cm}^{-2}$ was achieved.

\section{Introduction}

Polymer electrolyte membrane fuel cells (PEMFCs) are a promising alternative for portable power applications due to their high energy conversion efficiency, low temperature operation, high power and energy density of their fuel sources, so giving the technology certain advantages over batteries (1). Existing research is well developed in the use of graphite flow field plates (FFPs) as current collectors. However, the increasing importance of compact design have resulted in the need for innovative solutions in order to maximize power density and for ease of system integration (2). The use of alternative cell and stack designs - such as open cathode configurations or materials - such as printed circuit board (PCB) fuel cells, offer routes to low-cost and design flexibility.

PCBs are used extensively in various applications in the electronics industry. They are made up of a thin layer of copper placed upon a support layer, usually FR4 (made of epoxy resin and glass fibre). They are known for their adaptability, durability and manufacturability, which make them advantageous for use in fuel cell stacks, where strong and lightweight design is desired. However, new designs and ways of making cells and stacks require a robust way of characterising their performance and a systematic approach to optimization. Previous experimental research on the characterisation and optimization of self-breathing fuel cell performance has focussed most analysis on polarization data (3-5). In this study, electrochemical impedance spectroscopy (EIS) 
alongside polarisation results are used to characterise the effect of cathode opening ratios on the loss mechanisms that contribute to the overall fuel cell performance.

Self-breathing PEMFCs are attractive for portable power application sources because unlike forced convection fuel cells they do not require active convection of air to cathodes. This is of vital importance for portable application where simple construction and minimum balance-of-plant are required. In self-breathing fuel cells, the cathode is exposed to the atmosphere and supply of oxygen is achieved through free or natural convection of air-flow $(6,7)$. The output power densities of these types of fuel cells are typically low when compared with forced convection fuel cells with the cathode performance the major source of voltage loss as a result of the relatively weak mechanism of natural convection of air which leads to significant mass transport limitations (8). They are also susceptible to flooding as water removal is mainly due to evaporation (9). However, key advantages over forced convection designs such as simplicity, no parasitic loads associated with pumps or compressors, lower cost, less noise and a smaller system means that they are still an active area of development.

Electrochemical impedance spectroscopy (EIS) is a powerful diagnostic tool that can characterise the various losses in a fuel cell (10-12). The main advantage of EIS is that it is non-destructive and provides information about fuel cell performance without (substantially) perturbing the system from equilibrium (13). EIS has been used to decouple anode and cathode operation, optimise MEA fabrication and fuel cell operating conditions, and examine the effect of cell compression and water management in operating systems (13-15). It was also recently used by Meyer et al. (16) to investigate the flooding effect in a dead ended anode fuel cell, with a novel reconstructed impedance technique.

Thermal imaging is a technique which utilises emitted infrared radiation in order to accurately measure the surface temperature of devices, often using a semiconducting detector. It is increasingly being employed to measure the temperature distribution of operational fuel cells. Unlike traditional thermocouple measurements which cannot access the spatially dependant nature of temperature in PEFCs, infrared imaging enables a highly resolved spatial measurement. Optical access to the fuel cell electrodes is usually gained using various infrared windows such as zinc selenide and barium fluoride. The open-cathode design helps alleviate the issues associated with accessing the GDL surface as it provides direct access to the electrode surface, hence no need for optical windows. Such a design enables surface temperature measurements of both the MEA and the PCB 'land' area. 


\section{Experimental}

The self-breathing PEFC consisted of two printed circuit board (PCB) current collectors (anode and cathode), an MEA, gaskets and two end-plates. The PCB current collectors were $1.6 \mathrm{~mm}$ thick and were coated with conductive carbon-based ink for corrosion protection. A double-serpentine flow-field geometry was used for the anode, as shown in Error! Reference source not found.a where the channel width, land and depth are all $1 \mathrm{~mm}$.

(a)

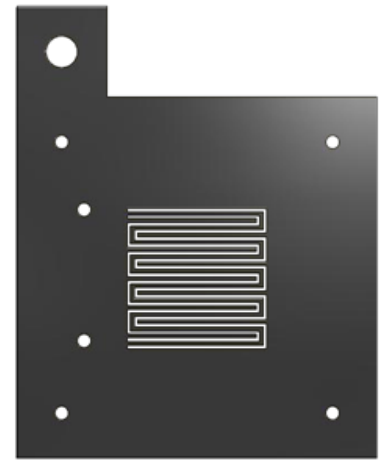

(b)
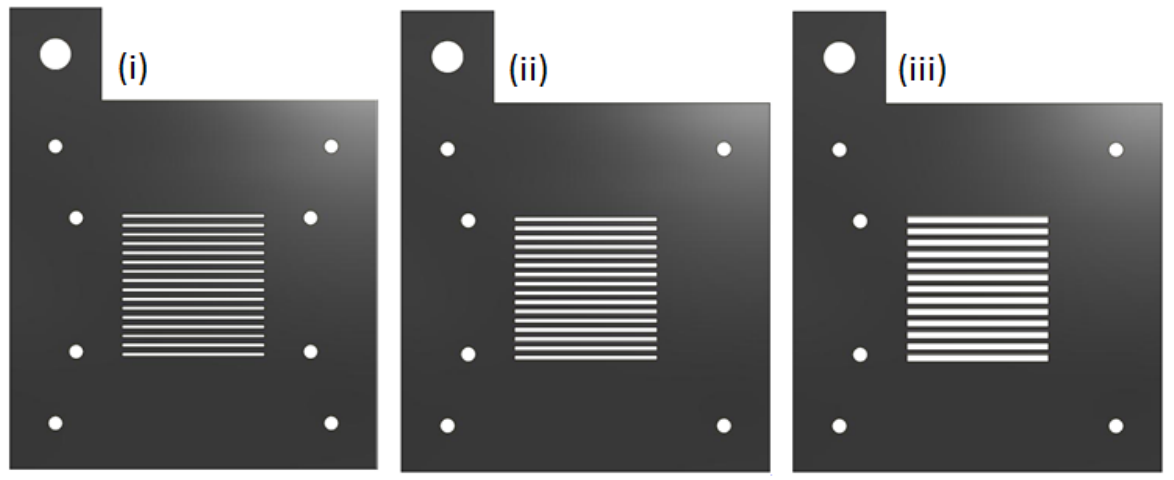

Figure 1(a) Anode flow field plate (b) Cathode flow field plate designs for the parallel geometry at different opening ratios (i) $42 \%$ (ii) $52 \%$ (iii) $62 \%$

In order to study the effect of cathode opening ratios on self-breathing fuel cell performance, three sets of channel dimensions were employed for the parallel geometry (Error! Reference source not found.(b)). Details of the dimensions used for both cathode geometries are shown in Table 1.

TABLE I. Details of the current collector geometry design.

\begin{tabular}{cccc}
\hline Opening ratio & $\begin{array}{c}\text { Channel width / } \\
\mathbf{m m}\end{array}$ & Land width / mm & $\begin{array}{c}\text { Number of } \\
\text { channels }\end{array}$ \\
\hline $43 \%$ & 0.8 & 1.2 & 16 \\
$53 \%$ & 1.0 & 1.0 & 16 \\
$63 \%$ & 1.6 & 1.0 & 13 \\
\hline
\end{tabular}


Figure 2(a) shows the structure of the test cell. The cathode end-plates were made from aluminium and contained a $13 \mathrm{~cm} 2$ square window for direct visualization of the flowfield, as shown in Figure 2(b). This allowed the same end-plates to be used for the different cathode geometries. A torque of $3.6 \mathrm{Nm}$ was applied to each of the four tie bolts to put the cell into compression.

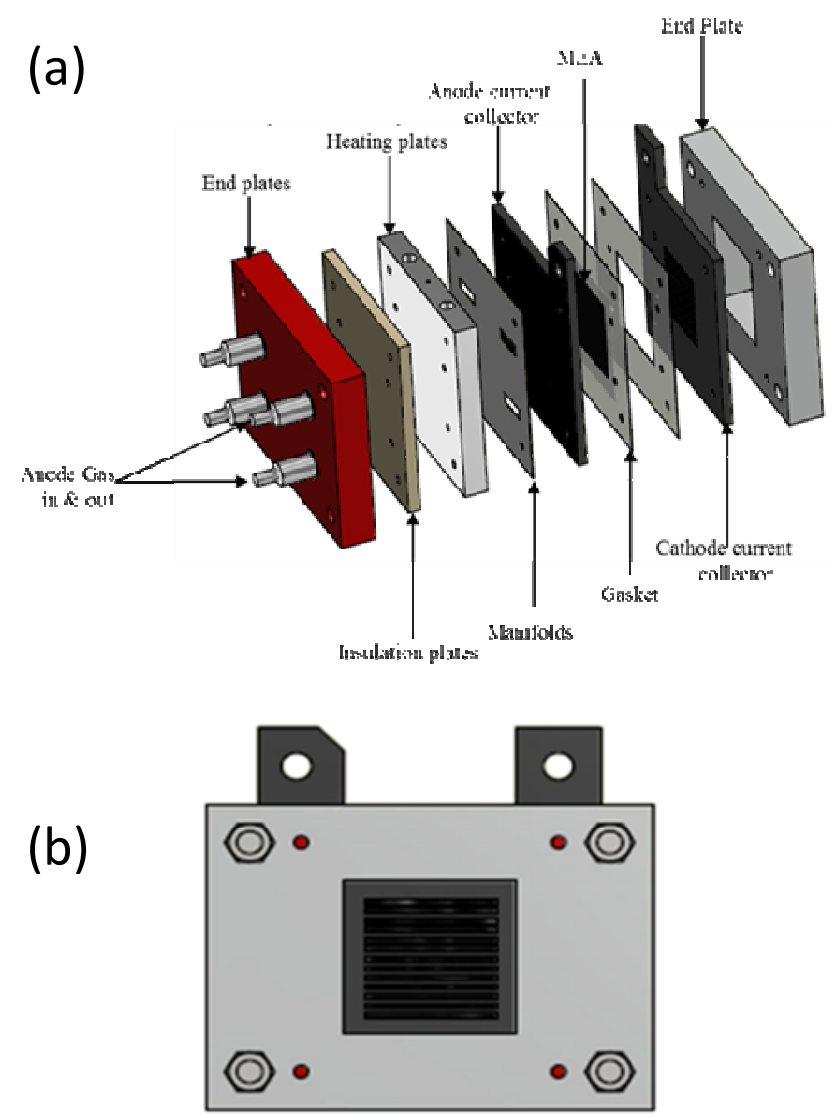

Figure 2(a) Exploded view of the open cathode fuel cell; (b) view of the open cathode.

Fuel cell operation was carried out using a Scribner 840 advanced fuel cell test system (Scribner Associates NC, USA). The test rig combines a computer-controlled instrument (integrated multiple current-range programmable electronic load, fuel and temperature controls, data acquisition functions and a built-in frequency response analyser) with fuel handling hardware in an integrated bench-top unit. It includes complete reactant gas conditioning capabilities (humidification and mass flow controllers) and is controlled using FuelCell software. Hydrogen (99.995\% purity, BOC UK) was supplied at a rate of $100 \mathrm{~cm}^{3} \mathrm{~min}^{-1}$. Experiments were carried out at ambient conditions, which were measured to be around $25{ }^{\circ} \mathrm{C}, 40 \%$ relative humidity and 1.02 bar (Abs). The fuel cell assembly was in a vertical orientation. Current sweep experiments were conducted in steps of $0.48 \mathrm{~A}\left(50 \mathrm{~mA} \mathrm{~cm}^{-2}\right)$ for $60 \mathrm{~s}$ per point and the corresponding cell voltage was recorded. Electrochemical impedance spectroscopy measurements were carried out using a LabVIEW based frequency response analyser (UCL-FRA) developed in-house and described previously (17). Measurements were made over a frequency range 
of $5 \mathrm{kHz}$ to $0.1 \mathrm{~Hz}$ with 10 frequency points taken per decade with an AC amplitude of $5 \%$ of the DC signal.

\section{Experimental Results and Discussion}

\section{Effect of cathode opening ratio on the performance of the parallel geometry}

Three sets of channel opening ratios were fabricated to determine the effect of changing the opening ratios on the performance of the parallel opening geometry. It can be observed from Error! Reference source not found. that the fuel cell performance using this geometry is strongly affected by the opening ratio. It is however dependent upon the current density. At lower current densities $\left(\leq 100 \mathrm{~mA} \mathrm{~cm}^{-2}\right)$, for example 100 $\mathrm{mA} \mathrm{cm}{ }^{-2}$, the cell voltage reduced from $0.74 \mathrm{~V}$ at $42 \%$ opening ratio to $0.70 \mathrm{~V}$ at $62 \%$ opening ratio. At this region, activation loss and ohmic resistance are the major sources of voltage loss and the result indicates they increase with opening ratio when using parallel opening geometries. This is as a result of the reduced contact between the gas diffusion layer and flow field plate as opening ratio increases due to the lower rib (land) area. Increasing the opening area could also result in faster evaporation of liquid water and hence lower ionic resistance of the electrolyte.

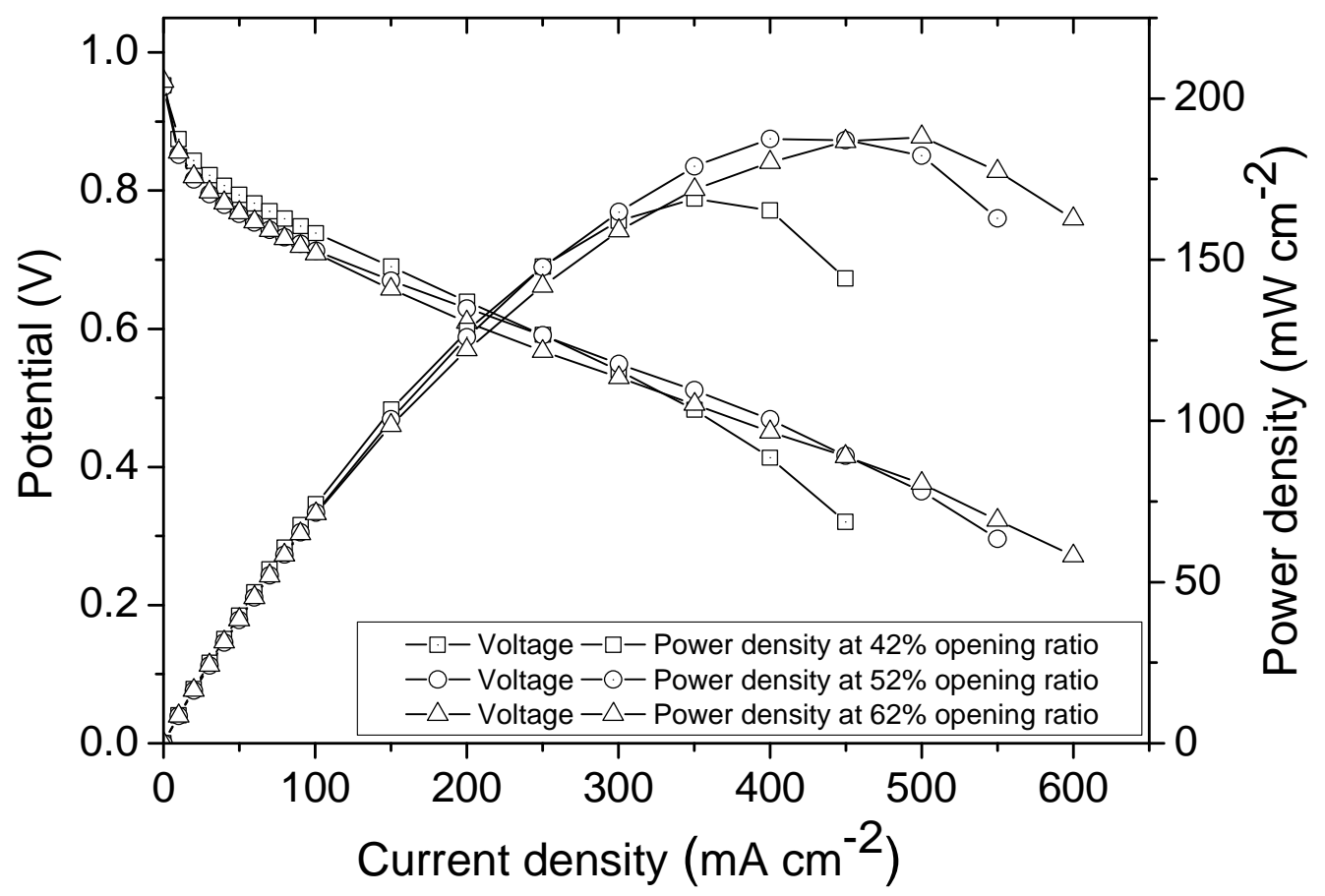

Figure 3 Polarisation performance comparison of open-cathode fuel cell with parallel openings with different opening ratios.

However, as the current density increases there is a gradual change in trend, with the performance of the design with the lower opening ratios affected more by mass transport limitation effect. Furthermore, the design with the highest opening ratio $(62 \%)$ has a higher limiting current density $\left(\sim 600 \mathrm{~mA} \mathrm{~cm}^{-2}\right)$. This is due to the improved transport of oxygen to the catalyst area as opening ratios increases. Smaller openings also limits water 
egress as evaporation is not as fast the larger ones. At high current densities this could also hinder oxygen diffusion especially to the rib of the flow field plate effectively reducing the current density. A maximum power density of $188 \mathrm{~mW} \mathrm{~cm}^{-2}$ at current density of $400 \mathrm{~mA} \mathrm{~cm}^{-2}$ and $500 \mathrm{~mA} \mathrm{~cm}$ was achieved for the single cell with $52 \%$ opening ratio and $62 \%$ opening ratios respectively.

\section{Electrochemical impedance spectroscopy analysis of channel geometry}

To provide further insight into the various loss mechanisms that contribute to overall fuel cell performance EIS was performed.
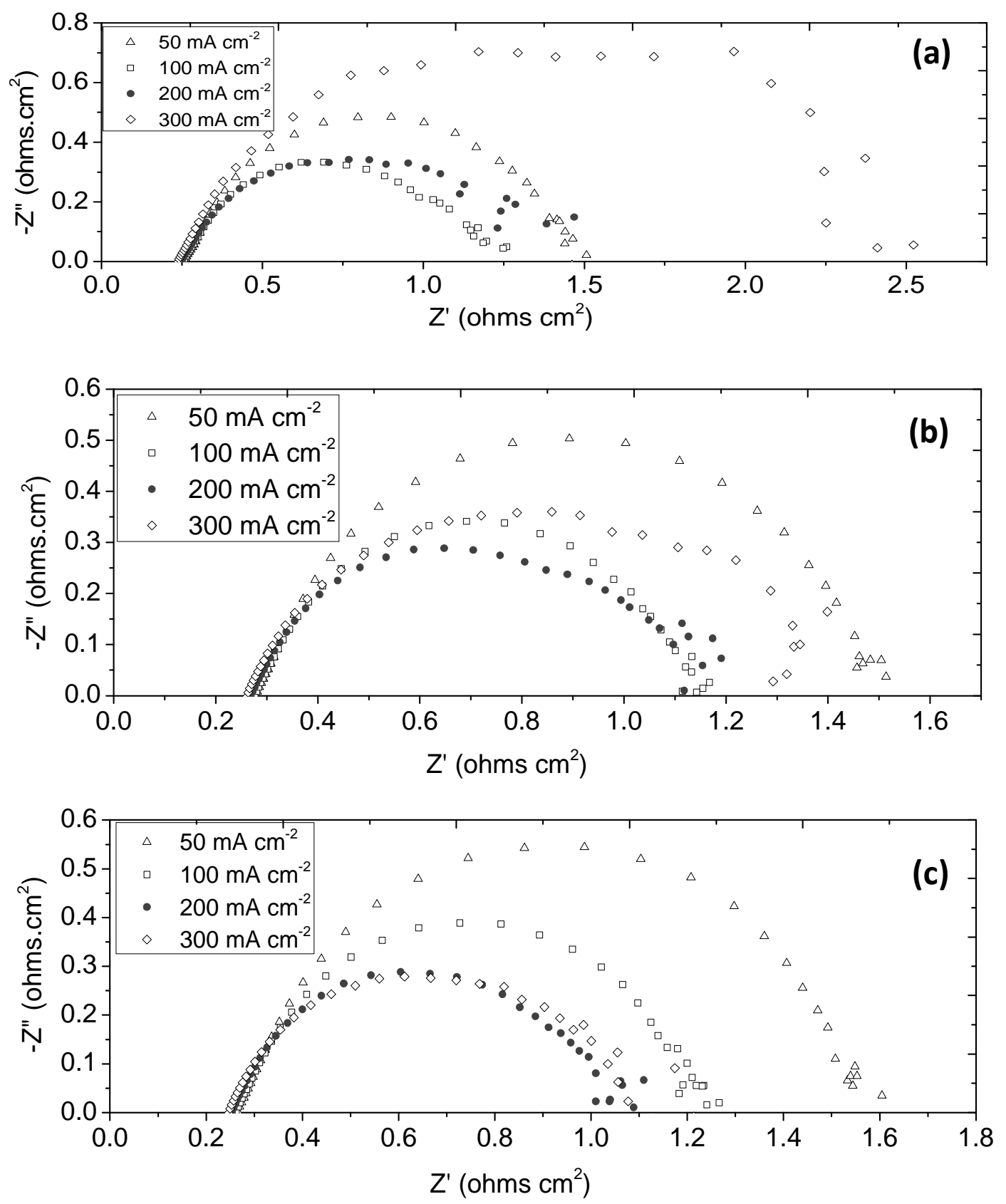
Figure 4 Nyquist plots for the parallel opening slot geometries at different current densities - opening ratios of: (a) $42 \%$, (b) $52 \%$ and (c) $62 \%$.

Figure 4 shows the EIS response for different channel opening ratios at various current densities, $50 \mathrm{~mA} \mathrm{~cm}{ }^{-2}, 100 \mathrm{~mA} \mathrm{~cm}^{-2}, 200 \mathrm{~mA} \mathrm{~cm}^{-2}$ and $300 \mathrm{~mA} \mathrm{~cm}^{-2}$. At the high frequency limit, each exhibits the same trend: with increasing current density, the high frequency intercept with the real axis shifts to lower values as shown in Figure 4, representing improved lower ionic resistance due to greater production of liquid water as current is increased. Furthermore, in all three opening ratios, the main arc is not clearly resolved into the contribution from electrode kinetics and mass transport limitations. However similar trends are displayed. On increasing the current density from $50 \mathrm{~mA} \mathrm{~cm}-$ 2 - $200 \mathrm{~mA} \mathrm{cm-}{ }^{2}$, there is a reduction in the arc associated with the electrokinetic overpotential in all three opening ratios. When fuel cell performance is dominated mainly by the oxygen reduction reaction (ORR) especially at the low current densities, the Nyquist plot represents mainly the charge transfer resistance associated ORR and the arc reduces as current density increases and therefore the effect of electrokinetic overpotential reduces. Increasing the current density to $300 \mathrm{~mA} \mathrm{~cm}$-2 results in a significant increase in the arc associated with mass transport limitations indicating the depletion oxygen in the cathode catalyst site - such an EIS response trend with PEMFC polarisation is well known from the literature $(13,18)$.

\section{High frequency intercept}

The high frequency intercepts (ohmic resistance) with the real axis obtained from the Nyquist plots in Figure 4 is plotted in order to clearly see the influence that opening geometries (Figure 5).

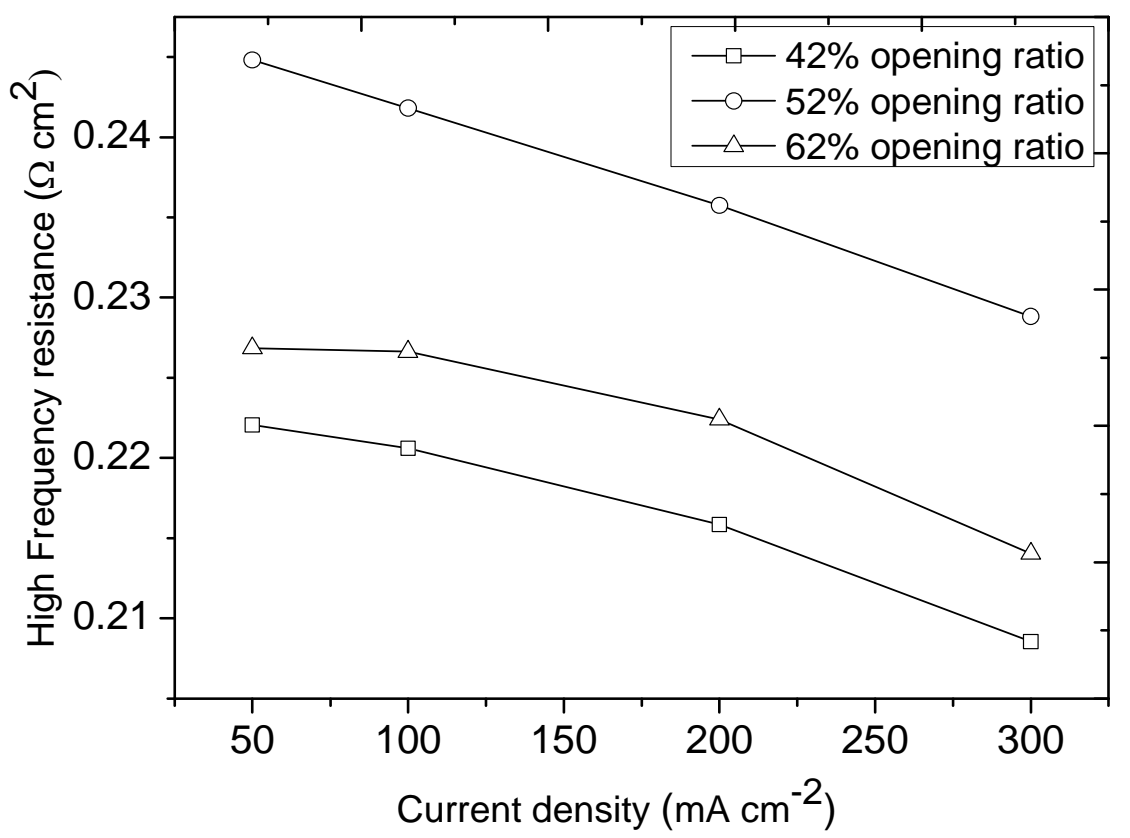

Figure 5 Relationship between the high frequency intercept and current density for different parallel opening ratios. 
All three opening ratios exhibit a decrease in high-frequency resistance (HFR) with increasing current density (Figure 5). This is attributed to improved ionic conductivity as the membrane becomes more hydrated (greater water production at higher current density). Furthermore, an increase in the opening ratio is positively correlated with an increase in the Ohmic resistance of the fuel cell due to greater contact between the gas diffusion layer and flow field, as a result of the higher land fraction with smaller opening ratios.

\section{Thermal imaging}

The images of the cathode temperature field (central channel) at different current densities are shown in Figure 6. It is seen that an increase in current density leads to an increase in the temperature which is due to increased electrochemical reaction and therefore heat generation. The temperature field was captured $90 \mathrm{~s}$ after each electrical loading. It is seen that an increase in current density leads to an increase in the temperature which is due to increased electrochemical reaction and therefore heat generation. There is also non-uniform temperature distribution within the fuel cell which is as a result of the metal body surround acting as a heat sink which reduces temperature at the periphery. The middle of the cell displays a minimum in temperature which is more pronounced with increasing opening ratio. This could be as a result of reduced current density distribution as a result of the "bowing" of the PCB. Increased opening ratio will result in a weaker structure and hence more severe bowing, resulting in lower temperatures in the middle of the cell at higher opening ratios.

(a)

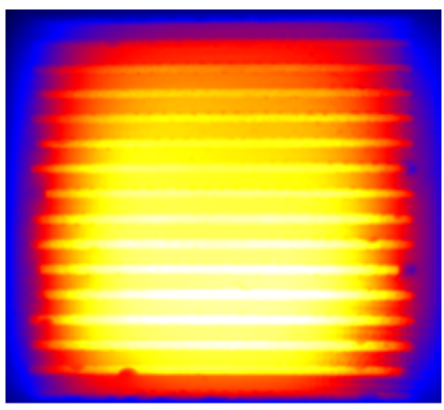

$42 \%$

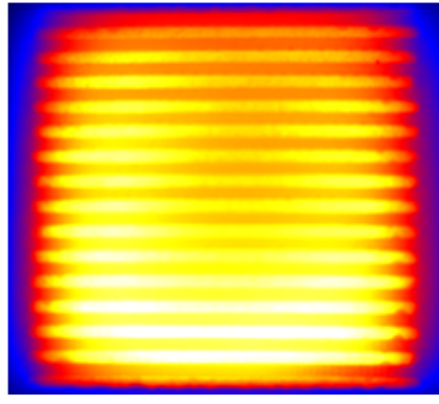

$52 \%$

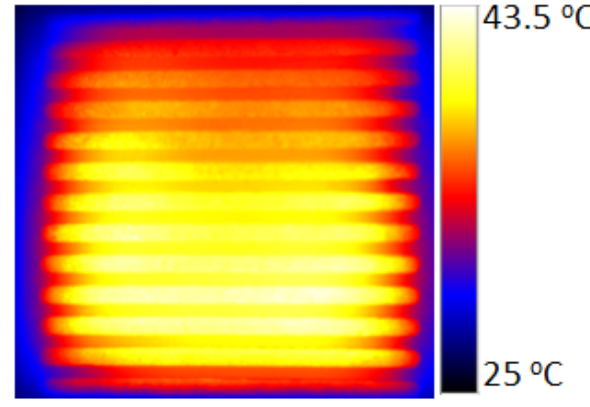

$62 \%$
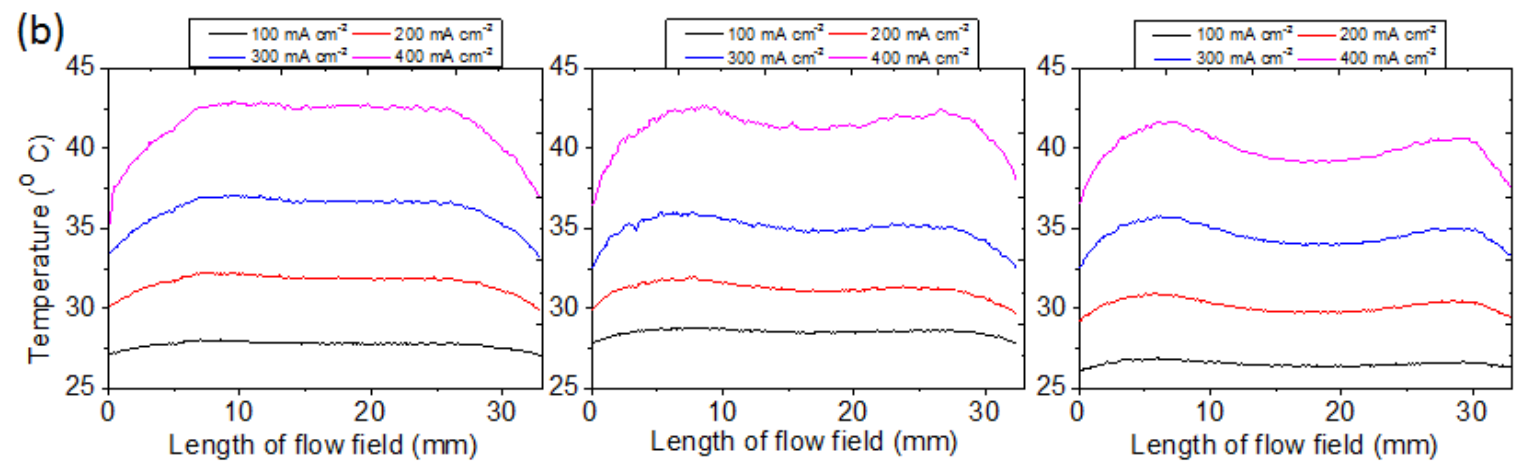

Figure 6(a) Temperature profile of the parallel opening ratios at $400 \mathrm{~mA} \mathrm{~cm}^{-2}$; (b) processed temperature data for different opening ratios at various current densities horizontally across the central channel of the fuel cell. 


\section{Conclusion}

Performance of a self-breathing fuel cell designed using printed circuit board current collectors has been demonstrated. The effect of cathode opening ratios on performance was characterised using polarization curves and electrochemical impedance spectroscopy. The results reveal that the influence of cathode opening ratios on selfbreathing fuel cell performance is dependent on the current density. Smaller opening ratios have better performance at lower current densities due to decreased Ohmic resistance and while their performance deteriorates at higher current densities due to mass transport limitations. This means that the choice of design will be determined by the application and the desired operational range on the polarisation curve.

\section{Acknowledgments}

The authors would like to acknowledge Sunshine Oil and Chemical Development Company Limited for supporting Obeisun's Ph.D. scholarship and the EPSRC for funding the Electrochemical Innovation Lab's fuel cell research programme through (EP/K038656/1; EP/G060991/1; EP/J001007/1; EP/I037024/1; EP/G030995/1; EP/G04483X/1). PRS acknowledges the Royal Academy of Engineering for funding support.

\section{References}

1. R. O'Hayre, T. Fabian, S.-J. Lee and F.B. Prinz, Journal of The Electrochemical Society 150, A430 (2003).

2. D.J.L. Brett and N.P. Brandon, Journal of Fuel Cell Science and Technology 4, 29 (2007).

3. W. Ying, T.-H. Yang, W.-Y. Lee, J. Ke and C.-S. Kim, Journal of Power Sources 145, 572 (2005).

4. N. Bussayajarn, H. Ming, K.K. Hoong, W.Y. Ming Stephen and C.S. Hwa, International Journal of Hydrogen Energy 34, 7761 (2009).

5. Z. Williamson, D. Kim, D.-K. Chun, T. Lee and C. Squibb, Applied Thermal Engineering 31, 3761 (2011).

6. S.U. Jeong, E.A. Cho, H.-J. Kim, T.-H. Lim, I.-H. Oh and S.H. Kim, Journal of Power Sources 158, 348 (2006).

7. W. Ying, J. Ke, W. Lee, T. Yang and C. Kim, International Journal of Hydrogen Energy 30, 1351 (2005).

8. B. Babcock, a. J. Tupper, D. Clark, T. Fabian and R. O’Hayre, Journal of Fuel Cell Science and Technology 7, 021017 (2010).

9. N. Karst, V. Faucheux, A. Martinent, P. Bouillon, J.-Y. Laurent, F. Druart and J.P. Simonato, Journal of Power Sources 195, 1156 (2010).

10. X. Yuan, H. Wang, J. Colinsun and J. Zhang, International Journal of Hydrogen Energy 32, 4365 (2007).

11. M.U. Iftikhar, D. Riu, F. Druart, S. Rosini, Y. Bultel and N. Retière, Journal of Power Sources 160, 1170 (2006). 
12. S.M. Rezaei Niya and M. Hoorfar, Journal of Power Sources 240, 281 (2013).

13. S. Asghari, A. Mokmeli and M. Samavati, International Journal of Hydrogen Energy 35, 9283 (2010).

14. T.J. Mason, J. Millichamp, T.P. Neville, A. El-kharouf, B.G. Pollet and D.J.L. Brett, Journal of Power Sources 219, 52 (2012).

15. T.J. Mason, J. Millichamp, T.P. Neville, P.R. Shearing, S. Simons and D.J.L. Brett, Journal of Power Sources 242, 70 (2013).

16. Q. Meyer, S. Ashton, O. Curnick, T. Reisch, P. Adcock, K. Rnaszegi, J.B. Robinson and D.J.L. Brett, Journal of Power Sources 254, 1 (2013).

17. Q. Meyer, S. Barass, O. Curnick, T. Reisch and D.J.L. Brett, Journal of Electrochemical Science and Engineering 3, 107 (2013).

18. M. Pérez-Page and V. Pérez-Herranz, International Journal of Electrochemical 6, 492 (2013). 